\title{
Synthesis of ligand-free CZTS nanoparticles via a facile hot injection route
}

Mirbagheri, Naghmehalsadat; Engberg, Sara Lena Josefin; Crovetto, Andrea; Simonsen, Søren Bredmose; Hansen, Ole; Lam, Yeng Ming; Schou, Jørgen

Published in:

Nanotechnology

Link to article, DOI:

$10.1088 / 0957-4484 / 27 / 18 / 185603$

Publication date:

2016

Document Version

Peer reviewed version

Link back to DTU Orbit

Citation $(A P A)$ :

Mirbagheri, N., Engberg, S. L. J., Crovetto, A., Simonsen, S. B., Hansen, O., Lam, Y. M., \& Schou, J. (2016). Synthesis of ligand-free CZTS nanoparticles via a facile hot injection route. Nanotechnology, 27(18), [185603]. https://doi.org/10.1088/0957-4484/27/18/185603

\section{General rights}

Copyright and moral rights for the publications made accessible in the public portal are retained by the authors and/or other copyright owners and it is a condition of accessing publications that users recognise and abide by the legal requirements associated with these rights.

- Users may download and print one copy of any publication from the public portal for the purpose of private study or research.

- You may not further distribute the material or use it for any profit-making activity or commercial gain

- You may freely distribute the URL identifying the publication in the public portal 


\title{
Synthesis of ligand-free CZTS nanoparticles via a facile hot injection route
}

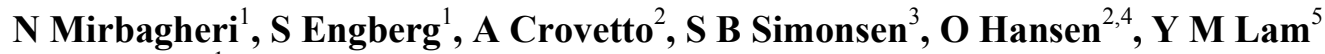 \\ and $\mathbf{J}$ Schou ${ }^{1}$ \\ ${ }^{1}$ DTU Fotonik, Technical University of Denmark, DK-4000 Roskilde, Denmark \\ ${ }^{2}$ DTU Nanotech, Technical University of Denmark, DK-2800 Kgs. Lyngby, Denmark \\ ${ }^{3}$ DTU Energy, Technical University of Denmark, DK-4000 Roskilde, Denmark \\ ${ }^{4}$ DTU Fysik, Technical University of Denmark, DK-2800 Kgs. Lyngby, Denmark \\ ${ }^{5}$ School of Materials Science and Engineering, Nanyang Technological University, 50 \\ Nanyang Avenue, 639798, Singapore \\ E-mail: sleen@fotonik.dtu.dk
}

\begin{abstract}
Single-phase, ligand-free $\mathrm{Cu}_{2} \mathrm{ZnSnS}_{4}$ (CZTS) nanoparticles that can be dispersed in polar solvents are desirable for thin film solar cell fabrication, since water can be used as the solvent for the nanoparticle ink. In this work, ligand-free nanoparticles were synthesized using a simple hot injection method and the precursor concentration in the reaction medium was tuned to control the final product. The as-synthesized nanoparticles were characterized using various techniques, and were found to have a near-stoichiometric composition and a phase-pure kesterite crystal structure. No secondary phases were detected with Raman spectroscopy or scanning transmission electron microscopy (TEM) energy dispersive X-ray spectroscopy. Furthermore, high resolution TEM showed large-sized nanoparticles with an average diameter of $23 \mathrm{~nm} \pm 11 \mathrm{~nm}$.

This approach avoids all organic materials and toxic solvents, that otherwise could hinder grain growth and limit the deposition techniques. In addition, the synthesis route presented here results in nanoparticles of a large size compared to other ligand-free CZTS nanoparticles, due to the high boiling point of the solvents selected. Large particle size in CZTS nanoparticle solar cells may lead to a promising device performance. The results obtained demonstrate the suitability of the synthesized nanoparticles for application in low cost thin film solar cells.
\end{abstract}

\section{Introduction}

With the growing power consumption and increase in environmental pollution caused by human activity, research and applications of alternative energy sources such as solar cells have received more attention than ever before. Among different types of solar cells, second-generation solar cells based on thin film technology have attracted considerable research effort in the last decade, mainly due to the increasing demand for earth abundant and inexpensive materials, $[1,2]$. The quaternary compound of copper zinc tin sulfide, $\mathrm{Cu}_{2} \mathrm{ZnSnS}_{4}$ (CZTS), has become particularly interesting, [3,4]. This nontoxic compound offers a direct band gap energy of approximately $1.5 \mathrm{eV}$ and a large above band edge absorption coefficient of $\sim 10^{4} \mathrm{~cm}^{-1}$, and thus has the potential to efficiently harvest solar energy, [5].

Cost-effective solar cell production not only requires the use of earth abundant materials, such as CZTS, but also needs economical fabrication processes. Fabrication processes of CZTS absorber layers can be generally classified into vacuum- and non-vacuum-based techniques. The non-vacuum processes have the advantage of a low cost and a high throughput compared to the vacuum-based techniques [6]. The non-vacuum-based techniques follow the general solution-processing route, where an ink of some sort is used to deposit a thin film, followed by a thermal treatment to obtain large grains. The ink for CZTS absorber layer formation is based on either a molecular or a nanoparticle ink, where the molecular inks consist of $\mathrm{Cu}-\mathrm{Zn}-\mathrm{Sn}-\mathrm{S}$ precursor salts in the right composition, and the 
nanoparticle inks of small CZTS grains already crystallized into the desired phase. The molecular inks are leading in power conversion efficiency, $\eta$, $\left(\eta=12.6 \%\left(\mathrm{Cu}_{2} \mathrm{ZnSn}\left(\mathrm{S}_{\mathrm{x}} \mathrm{Se}_{1-\mathrm{x}}\right)_{4}(\mathrm{CZTSSe})\right.\right.$ in hydrazine $)$ [7], $\eta=8.6 \%\left(\mathrm{Cu}_{2} \mathrm{ZnSnSe}_{4}\right.$ (CZTSe) in water/ethanol) [8], $\eta=5 \%$ (CZTS in water/ethanol) [9]), but the devices made from the nanoparticle inks are not far behind ( $\eta=9 \%$ (CZTSSe in hexanethiol) [10], $\eta=2.5 \%$ (CZTS in toluene) [11]). The nanoparticle ink approaches have the potential to control phase formation, particle size and surface properties of the synthesized nanoparticles, $[3,12,13]$. Synthesis of CZTS nanoparticles is most commonly carried out in the organic, non-polar solvent oleylamine, $[14,15]$. The resulting solution is then utilized as a nanoparticle ink for CZTS film formation using facile and cost-effective liquid coating methods such as spray coating [16], spin coating [17], and drop-casting [18]. The CZTS nanoparticles synthesized in organic, non-polar solvents bear long-chain carbon ligands as stabilizers, and are therefore hydrophobic. Hence, organic solvents, which are often expensive and toxic, are needed for the preparation of the nanoparticle ink. In addition, the stabilizers are left behind as hydrocarbon impurities in the produced CZTS film, and act as an insulating barrier that adversely affects the efficiency of the prepared absorber layer, [3,19,20]. Different approaches, such as growing larger nanoparticles to minimize the surface to volume ratio of the particles [21], or exchange of the long stabilizing ligands at the surface of CZTS nanoparticles with shorter carbon chain ligands [22,23], have been suggested to resolve this problem. However, these approaches suffer from the added complexity of the synthesis process, which eventually can affect the cost of solar cell fabrication, [3,20].

Alternatively, the use of polar solvents for the synthesis of CZTS nanoparticles using solution-based approaches has been reported; the methods can be divided into either the solvothermal method or the hot-injection method, [24-26]. These approaches offer a facile and efficient method for the synthesis of ligand-free CZTS nanoparticles, which, in contrast to the nanoparticles capped with long hydrocarbon chains, can be dispersed in environmental-friendly polar solvents to form nanoparticle inks. For example, Kush et al. [26] reported a simple hydrothermal synthesis of ligand-free CZTS nanoparticles (2-4 $\mathrm{nm}$ in diameter) in water. The nanoparticles were then used for the preparation of hydrophilic CZTS ink without employing any organic solvent. The as-prepared ink, which was reported to be stable for a week, was easily applied to a substrate to form a uniform thin film. In another work, Zaberca et al. [25] synthesized ligand-free CZTS nanoparticles in ethylene glycol using the solvothermal method. The as-synthesized sample, composed of nanoparticles with sizes ranging from 5 to $10 \mathrm{~nm}$, was used for the fabrication of low-defect, crack-free, sintered absorber layers.

When considering the device performance of pure sulfide-phase CZTS nanoparticle solar cells, the record efficiency device $(\eta=2.5 \%)$ consisted of large-sized, ligand-coated nanoparticles of $60 \mathrm{~nm}$, [11]. The annealing process is more challenging without selenium, and we hypothesize that larger particles are advantageous in these selenium-free devices. The best ligand-less device $(\eta=1.94 \%)$ had an average particle size of $10 \mathrm{~nm}$, and was made using the solvothermal method, with which it seems challenging to synthesize larger particles, [27].

Besides the hydrocarbon impurities, the elemental composition ratio of CZTS nanoparticles can significantly affect the efficiency of the fabricated CZTS absorber layer. It has previously been found that CZTS thin film solar cells with high conversion efficiency can be prepared with $\mathrm{Cu} /(\mathrm{Zn}+\mathrm{Sn})$ and $\mathrm{Zn} / \mathrm{Sn}$ composition ratios of 0.76-0.90 and 1.1-1.3, respectively, [28].

In this work, a simple and cost-effective hot injection method, inspired by the solvothermal synthesis approach, was employed for the synthesis of ligand-free CZTS nanoparticles with a larger particle size and targeted elemental composition. The influence of the amount of metal precursors on the elemental composition, phase purity, and crystalline phase composition of the synthesized nanoparticles was also investigated.

\section{Experimental}

\subsection{Chemicals}


Copper(II) chloride dihydrate $\left(\mathrm{CuCl}_{2} \cdot 2 \mathrm{H}_{2} \mathrm{O}, 99.999 \%\right)$, zinc acetate $\left(\mathrm{Zn}(\mathrm{OAc})_{2}, 99.99 \%\right)$, tin(IV) chloride pentahydrate $\left(\mathrm{SnCl}_{4} \cdot 5 \mathrm{H}_{2} \mathrm{O}, 98 \%\right)$, sulfur $(\mathrm{S}, 99.98 \%)$, diethylene glycol $\left(\mathrm{C}_{4} \mathrm{H}_{10} \mathrm{O}_{3}, \mathrm{DEG}\right.$, 99\%), and triethylenetetramine $\left(\mathrm{C}_{6} \mathrm{H}_{18} \mathrm{~N}_{4}\right.$, TETA, 97\%) were purchased from Sigma Aldrich and were used without further purification. Isopropanol (99.8\%) and ethanol (96\%) were purchased from Merck Millipore and VWR Chemicals, respectively. Deionized (DI) water was provided from Milli-Q-Water (Millipore Corp, $18.2 \mathrm{M} \Omega / \mathrm{cm}$ at $25^{\circ} \mathrm{C}$ ).

\subsection{Material synthesis}

Synthesis of CZTS nanoparticles was performed through the hot injection method. In a typical synthesis, calculated amounts of $\mathrm{CuCl}_{2} \cdot 2 \mathrm{H}_{2} \mathrm{O}, \mathrm{Zn}(\mathrm{OAc})_{2}$ and $\mathrm{SnCl}_{4} \cdot 5 \mathrm{H}_{2} \mathrm{O}$ were mixed with $7 \mathrm{ml}$ DEG in a round-bottom flask equipped with a reflux condenser. The reaction mixture was degassed for 20 min under stirring at room temperature and then the temperature was increased to $220^{\circ} \mathrm{C}$ while purging with nitrogen. Afterwards, a solution containing $1 \mathrm{mmol} \mathrm{S}, 0.5 \mathrm{ml}$ TETA and $1 \mathrm{ml}$ DEG was quickly injected to the flask while stirring the solution ( $\mathrm{S}$ was first dissolved in TETA and then DEG was added to this solution). The mixture was kept under stirring at $220^{\circ} \mathrm{C}$ for $2 \mathrm{~h}$, and thereafter the resulting mixture was allowed to naturally cool down to room temperature. The mixture was then dispersed in a solution of $10 \mathrm{ml}$ DI water and $10 \mathrm{ml}$ ethanol and the new mixture was transferred to a $50 \mathrm{ml}$ conical centrifuge tube. After ultrasonicating the collected product at a frequency of $42 \mathrm{kHz}$ for $10 \mathrm{~min}$, the mixture was centrifuged at $6000 \mathrm{rpm}$ for $10 \mathrm{~min}$ and the obtained precipitate was extracted. The precipitate was subsequently rinsed through dispersing in a solution mixture containing $5 \mathrm{ml} \mathrm{DI}$ water and $5 \mathrm{ml}$ ethanol, followed by centrifuging at $6000 \mathrm{rpm}$ for $10 \mathrm{~min}$. This procedure showed high reproducibility for synthesis of CZTS nanoparticles.

\subsection{Sample preparation for EDX, XRD, Raman, and XPS measurements}

The as-synthesized CZTS nanoparticles were dispersed in a solution containing $5 \mathrm{ml}$ DI water and 5 $\mathrm{ml}$ ethanol and ultrasonicated until a homogeneous ink was obtained. The prepared ink was deposited on a quartz or silicon substrate through a simple drop casting method, in which a drop of ink was casted over the substrate and dried with nitrogen at room temperature. This procedure was repeated three times in order to obtain a uniform and thick film of the nanoparticles on the substrate. For X-ray photoelectron spectroscopy (XPS) measurements, the sample surface was cleaned by a mild sputtering treatment using $200 \mathrm{eV} \mathrm{Ar}^{+}$and low current setting for $5 \mathrm{~min}$.

\subsection{Sample preparation for TEM analysis}

The sample for bright-field transmission electron microscopy (TEM) and selected area diffraction (SAD) was prepared by dispersing a small amount of the synthesized nanoparticles in isopropanol using sonication for one hour. Droplets of hexane were then added to the mixture and the solution was sonicated for another $30 \mathrm{~min}$. Afterwards, a droplet of the prepared ink was placed onto a Ni TEM grid with amorphous holey $\mathrm{SiO}_{2}$ and air-dried. The sample for dark-field TEM imaging and high annular angle dark field (HAADF) scanning transmission electron microscopy (STEM) analysis was prepared by mixing the synthesized nanoparticles with droplets of hexane followed by grinding of the mixture in a ceramic mortar to obtain a fine paste. The obtained paste was then dispersed in ethanol by sonication for two hours. A droplet of the prepared suspension was added to an Au TEM grid with a holey carbon support film and air-dried.

\subsection{Material characterization}


The elemental composition, crystal structure and phase of the samples were determined using energy dispersive X-ray spectroscopy (EDX), X-ray diffraction (XRD), and Raman spectroscopy, respectively. EDX experiments were performed with an accelerating voltage of $15 \mathrm{kV}$ with a Bruker Quantax 70 system integrated into a Hitachi TM3000 scanning electron microscope. The uncertainties of the elemental composition ratios given in the table 1 were calculated based on the standard deviation obtained for each element in the sample. XRD measurements were carried out in the $2 \theta$ range from $20^{\circ}$ to $65^{\circ}$ using a Bruker D8 Advance diffractometer at $40 \mathrm{kV}, 40 \mathrm{~mA}$ using $\mathrm{Cu} \mathrm{K}_{\alpha}$ radiation $\left(\lambda=1.5418 \AA\right.$ ) in Bragg-Brentano configuration, a step size of $0.01^{\circ}$, and a step time of 0.013 s. XRD peaks were identified manually after baseline subtraction using the program EVA and the peak patterns were matched to the relevant Joint Committee on Powder Diffraction Standards (JCPDS) files. Raman spectroscopic measurements on single spots were carried out using a DXR Raman Microscope from Thermo Scientific in backscattering configuration equipped with a laser beam of wavelength $455 \mathrm{~nm}$, a laser power of $0.4 \mathrm{~mW}$, and a spot size of $1 \mu \mathrm{m}^{2}$. Raman line-scans were performed over a length of $32 \mu \mathrm{m}$ with a step size of $2 \mu \mathrm{m}$ under the same conditions as applied for single-spot measurements.

Bright-field TEM imaging and SAD were performed by using a JEM 2100 equipped with a $\mathrm{LaB}_{6}$ source operated at $200 \mathrm{kV}$. High resolution TEM, dark-field TEM and STEM were performed in combination with EDX by using a JEM 3000F equipped with a field emission gun operated at 300 $\mathrm{kV}$, a HAADF STEM detector, and an Oxford Instruments EDX detector with an ultra-thin window. The HAADF STEM analysis was performed with nominal probe size of $0.5 \mathrm{~nm}$ and camera length of $15 \mathrm{~cm}$. From the acquired TEM images, particle sizes were measured by manually outlining the particle perimeters, using the software ImageJ and converting the measured projected particle areas to particle diameters using a circular approximation. The particle size measurement was challenged by particle agglomeration so that the particle perimeter was not always clearly defined. This problem increases with the thickness of the agglomerate, and the measurements were therefore preferentially performed at the thin regions of the agglomerates observed in bright-field TEM images. In addition, dark-field TEM images were analysed to make sure not to exclude larger particles in the thicker agglomerate regions. The measured diameters are presented in the form of particle size distributions with an optimum bin size calculated according to the work reported by Diaconis et al. [29]. The error on the average particle size was estimated to be $13 \%$ by considering $10 \%$ TEM magnification calibration error and the error that arose from the manual determination of the single particle size.

The surface composition and oxidation state of the elements were determined using an XPS Thermo Scientific K-Alpha instrument with monochromatized $\mathrm{Al} \mathrm{K}_{\alpha} \mathrm{X}$-ray source (hv=1486.68 eV). All binding energies were calibrated using the $\mathrm{C} 1 \mathrm{~s}$ peak at $284.55 \mathrm{eV}$ as a reference. The Fourier transform infrared (FTIR) measurement was carried for powder samples, and measured in air atmosphere on a Bruker Tensor 27 spectrometer after background correction. The external quantum efficiency (EQE) was measured using a homemade setup on a conventional soda lime glass $/ \mathrm{Mo} / \mathrm{CZTS} / \mathrm{CdS} / \mathrm{ZnO} / \mathrm{Al}-\mathrm{ZnO} / \mathrm{Al}$ solar cell device. Light from a halogen lamp was monochromated and focused onto a $0.5 \mathrm{~mm}$ diameter spot on this solar cell. The output current was measured in $10 \mathrm{~nm}$ wavelength steps at zero voltage bias and calibrated with a standard Si photodiode to yield the quantum efficiency of the device. The absorbance spectrum was measured with a Varian Cary $50 \mathrm{UV}$-Vis spectrophotometer for liquid samples.

\section{Results and Discussion}

Table 1 represents the elemental composition of the CZTS nanoparticles (samples A-H) synthesized from reaction mixtures containing different amounts of metal precursors. As can be seen from this table, the experimental conditions used for preparation of sample G resulted in CZTS nanoparticles with $\mathrm{Cu} /(\mathrm{Zn}+\mathrm{Sn})$ and $\mathrm{Zn} / \mathrm{Sn}$ composition ratios lying within the desired range of 0.76-0.90 and 1.11.3 , respectively, which were previously reported as the ideal composition ratios for CZTS films with a high photovoltaic performance, [28]. However, the XRD pattern of the synthesized material (figure 
1a, red line) revealed the presence of orthorhombic SnS secondary phase (JCPDS data file no.: 390354) along with the kesterite CZTS phase (JCPDS data file no.: 26-0575). The XRD measurements of all the synthesized materials in table 1 (figure 1a and figure S1, supplementary information), showed that only the conditions used for the synthesis of sample E resulted in the formation of nanoparticles with pure kesterite structure (figure 1a, black line). However, it should be noted that the $\mathrm{Cu} /(\mathrm{Zn}+\mathrm{Sn})$ composition ratio of sample $\mathrm{E}$ was slightly above the desired range of $0.76-0.90$.

\section{Table 1}

Further investigation on the phase composition of the synthesized nanoparticles was carried out using Raman spectroscopy as a complementary technique to XRD. Figure 1b shows the Raman spectra of the as-deposited films of sample $\mathrm{E}$ and $\mathrm{G}$. The Raman spectrum of sample $\mathrm{E}$ (figure $1 \mathrm{~b}$, black line) shows the CZTS characteristic Raman peaks consisting of strong peaks at 287 and $336 \mathrm{~cm}^{-1}$ along with a broad peak within the range of $368-373 \mathrm{~cm}^{-1}$, [30]. The Raman spectrum of sample G (figure $1 \mathrm{~b}$, red line) supports the formation of CZTS, though in this case the peak at $336 \mathrm{~cm}^{-1}$ is shifted to 331 $\mathrm{cm}^{-1}$, which indicates the existence of $\mathrm{Cu}-\mathrm{Zn}$ disorder within the CZTS lattice of this sample, [31]. The narrower Raman peaks observed for sample E revealed a higher crystallinity of this CZTS when compared to sample G. In addition, the Raman microscopy showed heterogeneity on the surface of sample $G$ with a number of bright spots or faceted structures (figure 2a). A Raman map (figure $2 b$ ) of part of the sample containing these structures (indicated as region I, II, and III in figure 2a) showed Raman peaks corresponding to the CZTS phase in regions I and III, whereas Raman peaks consistent with the orthorhombic SnS secondary phase were obtained in region II. These data agree well with the obtained XRD patterns for sample E and G. As both the XRD and Raman measurements demonstrated the good crystalline nature of the synthesized CZTS nanoparticles of sample E, and considering the near-stoichiometric composition obtained for this sample, we chose this sample for further chemical and optical characterization.

\section{//Figure 1//}

\section{//Figure 2//}

The morphology, crystal structure and size of nanoparticles of sample E were investigated using TEM. As can be seen in figure 3a, the synthesized nanoparticles are irregular and have faceted morphologies with a high tendency of being aggregated. The diameter of the synthesized nanoparticles (figure 3a and figure S2 in supplementary information) was found to be within the range of 2.5-81.5 nm with an average particle size of $23 \mathrm{~nm}$ with a standard deviation of $11 \mathrm{~nm}$ (figure $3 \mathrm{~b}$ ), which is among the largest CZTS nanoparticles synthesized in organic polar solvent, [25,27,32-34]. To observe the full particle size range, it was necessary to record images at different magnifications. The smallest particles were for instance only observed in HRTEM images (such as the insert in figure 3d). It should therefore be noted, that although representative images were aimed for, the particle size distribution (figure 3b) will necessarily be biased by the number of recorded images at each magnification. High resolution TEM image (figure 3c) and the corresponding Fast Fourier Transform pattern (figure 3c, inset) showed lattice fringes with an inter-planar spacing of $3.1 \AA$, which can be ascribed to the (112) plane of the kesterite CZTS (JCPDS data file no.: 26-0575). High resolution TEM imaging also helped us to identify some parts of the sample that at lower magnifications at first sight looked like amorphous structures (the area indicated by a red square in figure 3d). High resolution TEM images (figure 3d) of these areas, however, showed that they were composed of small nanoparticles (figure $3 \mathrm{~d}$, close-up). Figure $3 \mathrm{e}$ shows the SAD pattern of the synthesized nanoparticles, which also matched well with the kesterite CZTS phase and correspond to (112), (220), (312), (224), (008) and (332) planes (JCPDS data file no.: 26-0575). These data are consistent with the obtained XRD pattern of this sample and confirm the phase purity of sample E. In order to further clarify the elemental composition and distribution of the synthesized nanoparticles, the STEM-EDX elemental nanoscale mapping was conducted (figure S3, supplementary information). The obtained elemental 
maps confirmed the homogeneous distribution of the four constituent elements of CZTS among the nanoparticles. In addition the obtained STEM-EDX elemental maps revealed the absence of $\mathrm{ZnS}$ secondary phase in sample E.

\section{//Figure 3//}

In order to identify the oxidation state of copper, zinc, tin and sulfur elements in the synthesized CZTS nanoparticles of sample E, XPS measurements were carried out on sample E (figure 4). Figure 4a shows the $\mathrm{Cu} 2 \mathrm{p}$ core level spectrum at binding energy of 932.28 and $951.98 \mathrm{eV}$ corresponding to $\mathrm{Cu} 2 \mathrm{p}_{3 / 2}$ and $2 \mathrm{p}_{1 / 2}$, respectively. The absence of the satellite $\mathrm{Cu} 2 \mathrm{p}_{3 / 2}$ peak at $933.7 \mathrm{eV}$ is indicative of the absence of $\mathrm{Cu}$ (II) in this sample, [35]. The peak splitting of $19.7 \mathrm{eV}$ between $\mathrm{Cu} 2 \mathrm{p}_{1 / 2}$ and $2 \mathrm{p}_{3 / 2}$ peaks along with calculated Auger parameter of the copper electrons revealed that the oxidation state of copper is +1 , [36,37]. The resolved peaks in figure $4 \mathrm{~b}$ at 1021.88 and $1044.98 \mathrm{eV}$ with peak splitting of $23.1 \mathrm{eV}$ are attributed to $\mathrm{Zn} 2 \mathrm{p}_{3 / 2}$ and $2 \mathrm{p}_{1 / 2}$ levels, respectively, and indicate the presence of $\mathrm{Zn}^{2+}$ in this sample, [36]. The $\mathrm{Sn} 3 \mathrm{~d}_{5 / 2}$ and $3 \mathrm{~d}_{3 / 2}$ core level peaks at 486.68 and $495.08 \mathrm{eV}$ with peak separation of $8.4 \mathrm{eV}$ demonstrate $\mathrm{Sn}$ is in the form of $\mathrm{Sn}^{4+}$ (figure 4c), [36]. Finally, the observed $\mathrm{S}$ $\mathrm{p}_{3 / 2}$ and $2 \mathrm{p}_{1 / 2}$ peaks at 161.88 and $163.08 \mathrm{eV}$ confirm the presence of $\mathrm{S}$ as $\mathrm{S}^{2-}$ (figure $4 \mathrm{~d}$ ), [36]. The obtained elemental oxidation states are in good agreement with the oxidation states of $\mathrm{Cu}, \mathrm{Zn}, \mathrm{Sn}$ and $\mathrm{S}$ in a typical CZTS nanoparticle.

\section{//Figure 4//}

The absence of hydrocarbon ligands (capping ligands) at the CZTS nanoparticles of sample E was confirmed by using FTIR spectroscopy, which did not show any signal in the range of $2800-3000 \mathrm{~cm}$ ${ }^{1}$ corresponding to the $\mathrm{C}-\mathrm{H}$ vibrational frequency of the DEG and TETA solvents (figure 5a). The broad band at $3000-3700 \mathrm{~cm}^{-1}$ and the band at $1635 \mathrm{~cm}^{-1}$ are attributed to the $\mathrm{O}-\mathrm{H}$ stretching and $\mathrm{O}-$ $\mathrm{H}-\mathrm{O}$ scissors bending of water molecules in the sample, respectively (figure 5a), [38]. The optical band gap of the CZTS nanoparticles of sample E was estimated by measuring the EQE of a fabricated CZTS thin film solar cell. Extrapolating the linear region of the plot of $[E \ln (1-\mathrm{EQE})]^{2}$ versus the incident photon energy $(E)$ [39], (figure 5b) indicates that the synthesized nanoparticles have a band gap of $\sim 1.44 \mathrm{eV}$. The obtained band gap is in good agreement with the previously reported optimum band gap appropriate for the fabrication of the absorber layer, [40,41]. For the sake of completeness, we have included the absorbance spectrum of the synthesized nanoparticles (figure $5 \mathrm{~b}$, inset).

\section{//Figure 5//}

\section{Conclusion}

In summary, we employed a simple and cost-effective method for the synthesis of single-phase ligand-free CZTS nanoparticles with desired elemental composition in an organic polar solvent. The obtained results indicate that the as-synthesized CZTS nanoparticles have the appropriate crystalline phase, elemental oxidation state, band gap energy and particle size of the as-synthesized CZTS nanoparticles for solar cell applications. A comparison of the average size of the synthesized nanoparticles with literature data shows that the nanoparticles synthesized in this work are among the largest CZTS nanoparticles that have been synthesized in organic polar solvents. This is an important advantage of the presented synthesis method since large nanoparticles can potentially form large CZTS grains (after the annealing process), which implies that the film may possess less grain boundaries (recombination centers) per unit area. In addition, the elemental composition of the synthesized nanoparticles was very close to the experimentally observed ideal composition, [28]. The as-synthesized CZTS nanoparticles can be easily dispersed in cheap, stable and environmentally friendly polar solvents, such as water, in order to prepare CZTS ink and form absorber layers without employing any pre-deposition treatments. 


\section{Acknowledgements}

We greatly appreciate Jean-Claude Grivel's assistance with the FTIR measurement as well as Jørgen Stubager's technical assistance with the nanoparticle synthesis. This work was supported by a grant from the Danish Council for Strategic Research.

\section{References}

[1] Choubey P C, Oudhia A and Dewangan R 2012 Recent Res. Sci. Technol. 499

[2] Butler D 2008 Nature 454558

[3] Zhou H, Hsu W-C, Duan H-S, Bob B, Yang W, Song T-B, Hsu C-J and Yang Y 2013 Energy Environ. Sci. 62822

[4] Walsh A, Chen S, Wei S-H and Gong X-G 2012 Adv. Energy Mater. 2400

[5] Ito K and Nakazawa T 1988 Jpn. J. Appl. Phys. 272094

[6] Hibberd C J, Chassaing E, Liu W, Mitzi D B, Lincot D and Tiwari A N 2010 Prog. Photovoltaics 18434

[7] Wang W, Winkler M T, Gunawan O, Gokmen T, Todorov T K, Zhu Y and Mitzi D B 2014 Adv. Energy Mater. 41301465

[8] Larramona G, Bourdais S, Jacob A, Chone C, Muto T, Cuccaro Y, Delatouche B, Moisan C, Pere D and Dennler G 2014 J. Phys. Chem. Lett. 53763

[9] Larramona G, Bourdais S p, Jacob A, Choné C, Muto T, Cuccaro Y, Delatouche B, Moisan C, Péré D and Dennler G 2014 RSC Adv. 414655

[10] Miskin C K, Yang W-C, Hages C J, Carter N J, Joglekar C S, Stach E A and Agrawal R 2015 Prog. Photovoltaics 23654

[11] Mkawi E M, Ibrahim K, Ali M K M, Farrukh M A and Allam N K 2014 Chem. Phys. Lett. 608 393

[12] Mitzi D B, Gunawan O, Todorov T K, Wang K and Guha S 2011 Sol. Energy Mater. Sol. Cells 951421

[13] Rajesh G, Muthukumarasamy N, Subramanian E P, Venkatraman M R, Agilan S, Ragavendran V, Thambidurai M, Velumani S, Yi J and Velauthapillai D2015 Superlattices Microstruct. 77305

[14] Guo Q, Ford G M, Yang W-C, Walker B C, Stach E A, Hillhouse H W and Agrawal R $2010 \mathrm{~J}$. Am. Chem. Soc. 13217384

[15] Kameyama T, Osaki T, Okazaki K-i, Shibayama T, Kudo A, Kuwabata S and Torimoto T 2010 J. Mater. Chem. 205319

[16] Carrete A, Shavel A, Fontane X, Montserrat J, Fan J, Ibanez M, Saucedo E, Perez-Rodriguez A and Cabot A 2013 J. Am. Chem. Soc. 13515982

[17] Ilari G M, Fella C M, Ziegler C, Uhl A R, Romanyuk Y E and Tiwari A N 2012 Sol. Energy Mater. Sol. Cells 104125

[18] Guo Q, Hillhouse H W and Agrawal R 2009 J. Am. Chem. Soc. 13111672

[19] Kim Y, Woo K, Kim I, Cho Y S, Jeong S and Moon J 2013 Nanoscale 510183

[20] Azimi H, Hou Y and Brabec C J 2014 Energy Environ. Sci. 71829

[21] Engberg S, Li Z, Lek J Y, Lam Y M and Schou J 2015 RSC Adv. 596593

[22] van Embden J, Chesman A S R, Della Gaspera E, Duffy N W, Watkins S E and Jasieniak J J 2014 J. Am. Chem. Soc. 1365237

[23] Huang W, Li Q, Chen Y, Xia Y, Huang H, Dun C, Li Y and Carroll D L 2014 Sol. Energy Mater. Sol. Cells 127188

[24] Zaberca O, Gillorin A, Durand B and Chane-Ching J Y 2011 J. Mater. Chem. 216483

[25] Zaberca O, Oftinger F, Chane-Ching J Y, Datas L, Lafond A, Puech P, Balocchi A, Lagarde D and Marie X 2012 Nanotechnology 23185402

[26] Kush P, Ujjain S K, Mehra N C, Jha P, Sharma R K and Deka S 2013 Chemphyschem 142793 
[27] Tian Q, Xu X, Han L, Tang M, Zou R, Chen Z, Yu M, Yang J and Hu J 2012 CrystEngComm 14 3847

[28] Katagiri H 2015 Sulfurization of Physical Vapor-Deposited Precursor Layers Copper Zinc Tin Sulfide-Based Thin Film Solar Cells ed K Ito (Japan: Wiley) p 192

[29] Freedman D and Diaconis P 1981 Z. Wahrscheinlichkeitstheorie verw. Gebiete 57453

[30] Dimitrievska M, Fairbrother A, Fontane X, Jawhari T, Izquierdo-Roca V, Saucedo E and PerezRodriguez A 2014 Appl. Phys. Lett. 104021901

[31] Fontane X, Izquierdo-Roca V, Saucedo E, Schorr S, Yukhymchuk V O, Valakh M Y, PerezRodriguez A and Morante J R 2012 J. Alloys Compd. 539190

[32] Cao M and Shen Y 2011 J. Cryst. Growth 3181117

[33] Zhou Y-L, Zhou W-H, Du Y-F, Li M and Wu S-X 2011 Mater. Lett. 651535

[34] Flynn B, Wang W, Chang C-h and Herman G S 2012 Phys. Status Solidi A 2092186

[35] Fan J, Dai Y, Li Y, Zheng N, Guo J, Yan X and Stucky G D 2009 J. Am. Chem. Soc. 13115568

[36] Riha S C, Parkinson B A and Prieto A L 2009 J. Am. Chem. Soc. 13112054

[37] Vaccarello D, Tapley A and Ding Z 2013 RSC Adv. 33512

[38] Mojet B L, Ebbesen S D and Lefferts L 2010 Chem. Soc. Rev. 394643

[39] Zoppi G, Forbes I, Miles R W, Dale P J, Scragg J J and Peter L M 2009 Prog. Photovolt.: Res. Appl. 17315

[40] Persson C 2010 J. Appl. Phys. 107053710

[41] Ito K 2015 An Overview of CZTS-Based Thin-Film Solar Cells Copper Zinc Tin Sulfide-Based Thin Film Solar Cells ed K Ito (Japan: Wiley) p 29 
Table 1. Elemental composition of a selection of samples $(\mathrm{A}-\mathrm{H})$ synthesized by changing the amount of metal precursors in the reaction medium.

Figure 1. (a) XRD and (b) Raman spectra of sample E (black line) and sample G (red line) deposited on a silicon substrate. The characteristic CZTS Raman peaks appear at 287 and $336 \mathrm{~cm}^{-1}$ for sample $\mathrm{E}$, whereas the main peak is shifted to $331 \mathrm{~cm}^{-1}$ for sample G.

Figure 2. (a) Typical image of the surface of sample $G$ showing bright regions as surface heterogeneities, and (b) the corresponding Raman map of the area indicated by red lines in (a).

Figure 3. (a) TEM image, (b) size distribution histogram obtained for 287 nanoparticles, (c) high resolution TEM image, (d) bright-field TEM image and high resolution TEM image of the area indicated by a red square, and (e) SAD pattern of the as-synthesized CZTS nanoparticles of sample E. Inset of (c) shows a Fast Fourier Transform of the high resolution TEM image indicating lattice fringes that can be ascribed to the (112) plane of the kesterite.

Figure 4. XPS spectra of the as-synthesized CZTS nanoparticles of sample E: (a) Cu 2p, (b) Zn 2p, (c) Sn $2 d$ and (d) S 2p signals.

Figure 5. (a) FTIR spectrum, and (b) plot of $[E \ln (1-\mathrm{EQE})]^{2}$ versus photon energy $(E)$ of the assynthesized CZTS nanoparticles of sample E. The band gap is determined by extrapolating the linear region of the $[E \ln (1-\mathrm{EQE})]^{2}$ plot to find the intersect with the $\mathrm{x}$-axis. The inset in (b) shows the $\mathrm{UV}-\mathrm{Vis}$ spectrum. 
Table 1

\begin{tabular}{ccccccc}
\hline $\begin{array}{c}\text { Synthesized } \\
\text { sample }\end{array}$ & \multicolumn{7}{c}{$\begin{array}{c}\text { Metal precursors used for } \\
\text { synthesis (mmol) }\end{array}$} & $\begin{array}{c}\text { Elemental } \\
\text { composition } \\
\text { determined by } \\
\text { CuCl }\end{array}$ & $\mathrm{Zn}(\mathrm{OAc})_{2}$ & $\mathrm{SnCl}_{4}$ & $\mathrm{Cu} /(\mathrm{Zn}+\mathrm{Sn})$ & $\mathrm{Zn} / \mathrm{Sn}$ \\
\hline $\mathrm{A}$ & 0.50 & 0.40 & 0.25 & $\mathrm{Cu}_{2.5} \mathrm{Zn}_{0.5} \mathrm{Sn}_{1.0} \mathrm{~S}_{3.4}$ & $1.6 \pm 0.2$ & $0.54 \pm 0.08$ \\
$\mathrm{~B}$ & 0.50 & 0.60 & 0.25 & $\mathrm{Cu}_{2.2} \mathrm{Zn}_{0.9} \mathrm{Sn}_{1.0} \mathrm{~S}_{3.0}$ & $1.1 \pm 0.1$ & $0.9 \pm 0.1$ \\
$\mathrm{C}$ & 0.40 & 0.60 & 0.25 & $\mathrm{Cu}_{2.0} \mathrm{Zn}_{0.9} \mathrm{Sn}_{1.0} \mathrm{~S}_{3.1}$ & $1.1 \pm 0.2$ & $0.9 \pm 0.1$ \\
$\mathrm{D}$ & 0.40 & 0.60 & 0.20 & $\mathrm{Cu}_{2.3} \mathrm{Zn}_{1.5} \mathrm{Sn}_{1.0} \mathrm{~S}_{4.1}$ & $0.9 \pm 0.1$ & $1.5 \pm 0.2$ \\
$\mathrm{E}$ & 0.40 & 0.45 & 0.20 & $\mathrm{Cu}_{2.3} \mathrm{Zn}_{1.3} \mathrm{Sn}_{1.0} \mathrm{~S}_{4.0}$ & $1.02 \pm 0.09$ & $1.3 \pm 0.1$ \\
$\mathrm{~F}$ & 0.40 & 0.45 & 0.23 & $\mathrm{Cu}_{2.1} \mathrm{Zn}_{1.1} \mathrm{Sn}_{1.0} \mathrm{~S}_{3.6}$ & $1.01 \pm 0.09$ & $1.07 \pm 0.09$ \\
$\mathrm{G}$ & 0.35 & 0.50 & 0.23 & $\mathrm{Cu}_{1.9} \mathrm{Zn}_{1.3} \mathrm{Sn}_{1.0} \mathrm{~S}_{3.6}$ & $0.82 \pm 0.08$ & $1.3 \pm 0.1$ \\
$\mathrm{H}$ & 0.35 & 0.45 & 0.23 & $\mathrm{Cu}_{2.1} \mathrm{Zn}_{1.1} \mathrm{Sn}_{1.0} \mathrm{~S}_{3.6}$ & $0.95 \pm 0.09$ & $1.1 \pm 0.09$ \\
\hline
\end{tabular}


Figure 1
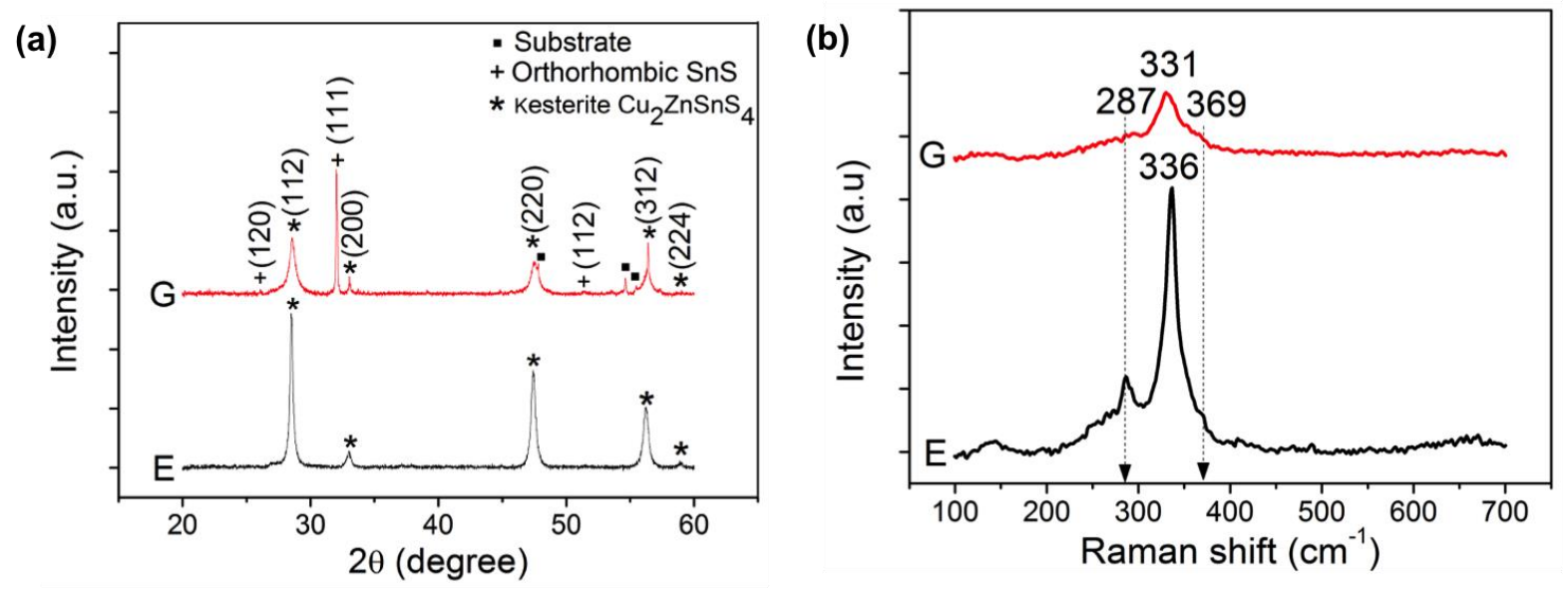
Figure 2
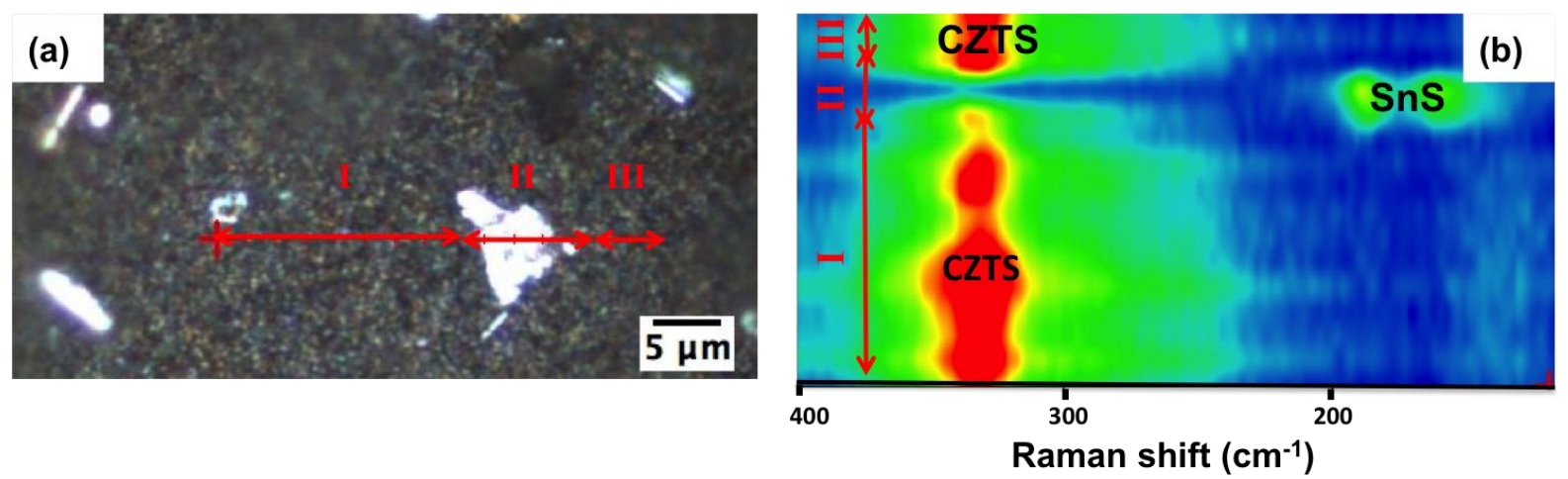
Figure 3
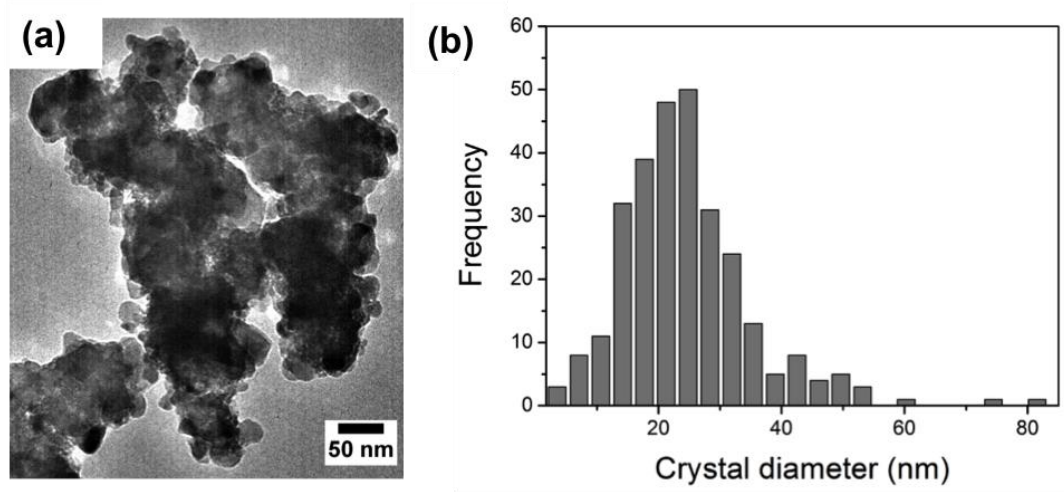

(d)

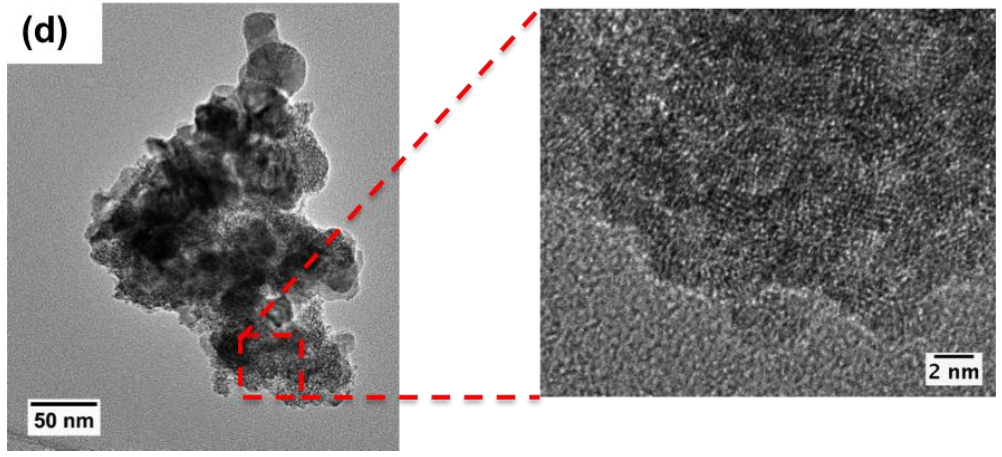

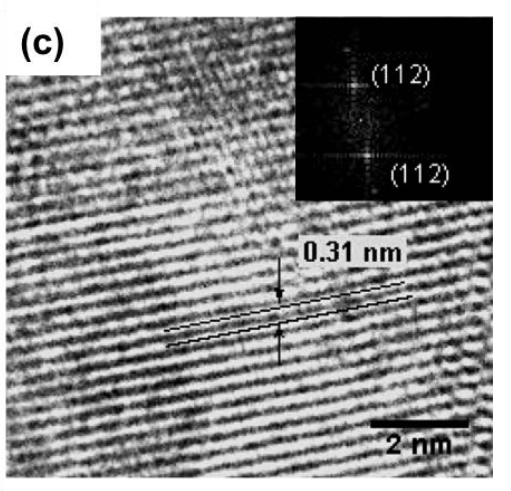

(e)

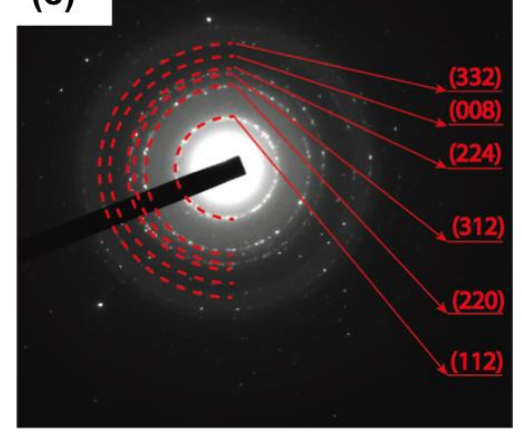


Figure 4

(a)

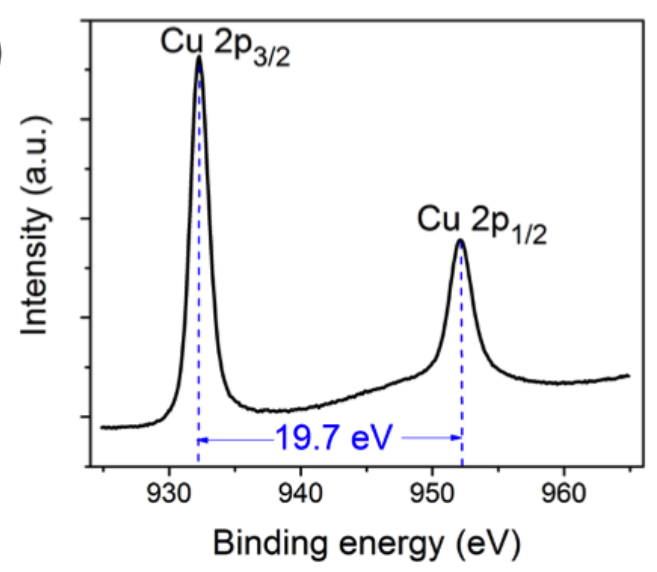

(c)

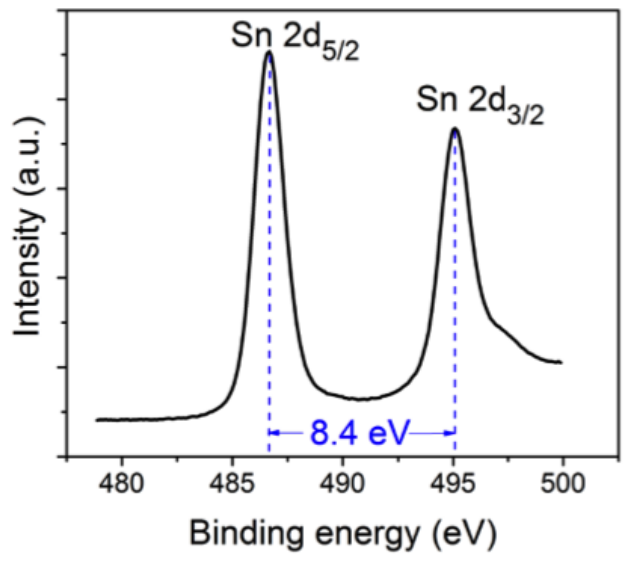

(b)

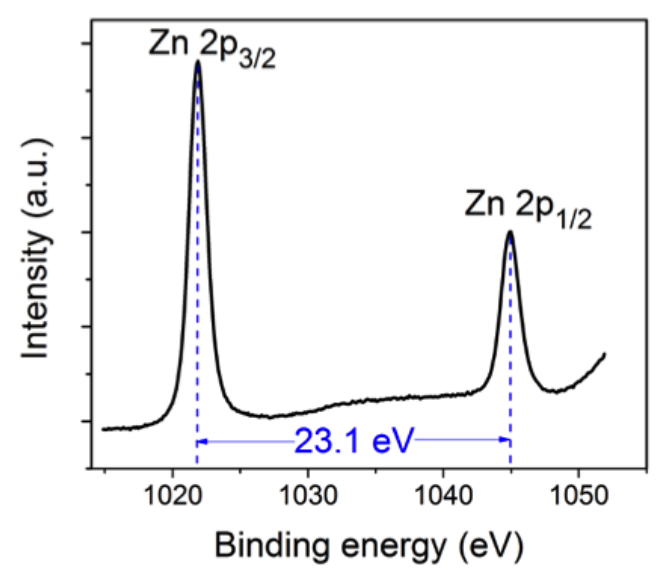

(d)

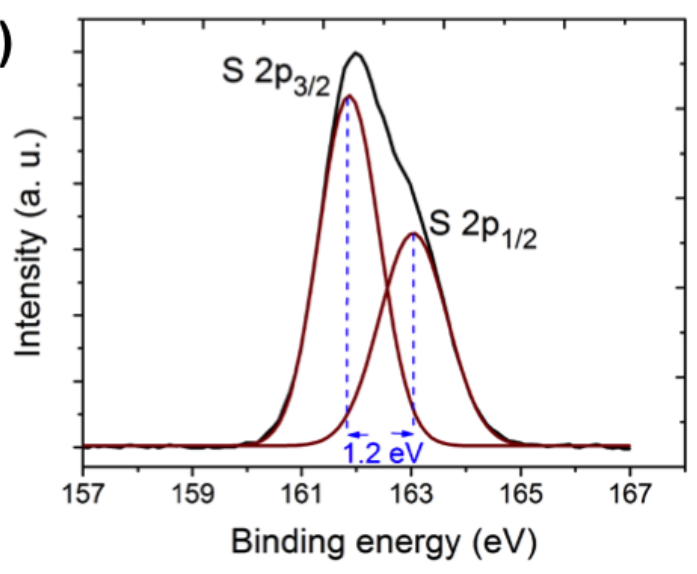




\section{Figure 5}
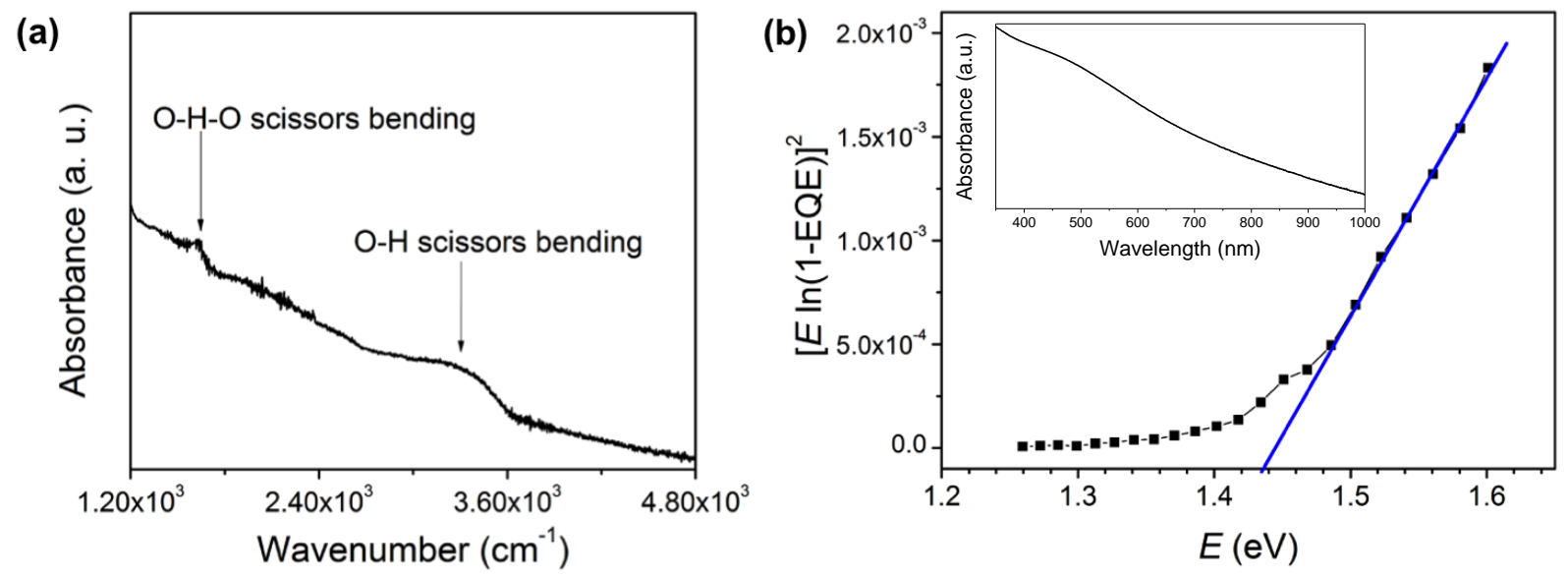